\title{
The Intricate Effects of Complexity and Personalization on Investment Intention in Robo-Advisory
}

\author{
Gregor Albrecht \\ Technical University of Darmstadt \\ albrecht@ise.tu-darmstadt.de
}

\author{
Jonas Toutaoui \\ Technical University of Darmstadt \\ toutaoui@ise.tu-darmstadt.de
}

\author{
Konstantin Roethke \\ Technical University of Darmstadt \\ roethke@ise.tu-darmstadt.de
}

\begin{abstract}
Amongst the tremendous transformation of the financial services industry in recent years, robo-advisory has emerged as new technology and proven its potential to digitalize this industry. Robo-advisors grant their users access to wealth management services that were historically performed manually. In doing so, robo-advisors allow personalization of investment portfolios on an unprecedented scale. Simultaneously, investment decisions are inherently complex for average users. Understanding how personalization and complexity affect users is, therefore, crucial for robo-advisors. We examine these effects in an online experiment with a fictitious robo-advisor and 169 participants. Our results show that personalization lowers users' intention to invest, while complexity has a significant positive effect on users' investment intentions and attenuates the negative impact of personalization. We contribute to IS research by uncovering the intricate effects of combining complexity and personalization in digital environments that will gain importance with users facing increasingly complex digital products.
\end{abstract}

\section{Introduction}

Digital technologies (e.g., mobile computing, cloud computing, digital platforms) are becoming increasingly ubiquitous. In recent years, not only new products but also completely new business models were moved to and created for a purely digital environment [1]. One example of such innovative business models is robo-advisory, which is an automated web-based investment advisory service. Robo-advisors offer automated, cost-effective, and easy-to-use wealth management to a theoretically unlimited audience [2]. Robo-advisors' popularity in recent years has grown significantly. With nearly $\$ 1$ trillion invested through robo-advisors worldwide in 2020 [3], it becomes more than apparent that robo-advisory is well beyond hype and that the financial services world is facing a significant shift of its form and boundaries away from traditional manual approaches towards innovative IT-enabled transactions [4].

Robo-advisors personalize investment portfolios presented to users before their investment decision. These portfolios are personalized to meet each user's boundary conditions-e.g., income [5]. Besides a high degree of web personalization, robo-advisors' primary product (i.e., investment portfolios) display a remarkable degree of complexity. This product complexity is reflected in the complexity of the user interface (i.e., website) — especially when users initially encounter the service: Due to regulatory requirements, robo-advisors are obliged to confront users with a multitude of detailed information for which users may lack financial knowledge $[6,7]$. As such, robo-advisors are an example of a new generation of web-based information systems (IS) that combine personalization and complexity at a large scale for average users, similarly to healthcare and real estate [8]. With more and more complex digital products and services being introduced, an understanding and optimized design of the combination of web personalization and website complexity is vital for business success (e.g., attract and retain users).

Indeed, web personalization is already a widely adopted strategy in information systems due to its various positive effects on user behavior $[9,10]$. While being an essential lever in digital environments, its adverse cognitive effects on users are also known and outlined extensively in IS research (e.g., $[11,12$, 13]. Especially in first interactions with users, a particularly critical touchpoint for digital enterprises, web personalization is prevalent and has shown negative effects such as discouraging users from adopting a product [13]. It remains unclear how all these effects might evolve when website complexity in digital products continues to increase. Previous IS research has proven website complexity to be a significant positive driver of users' attitudes towards a website 
such as user satisfaction $[14,15]$. Thereby, website complexity might be one of the scarce adequate tools to eliminate the negative effects of web personalization. Simultaneously, website complexity has also lead to inhibition of users' responses towards a website in some instances [16] and might also counter the positive effects of web personalization. Thus, understanding the intriguing effects of combining web personalization and website complexity is crucial to design successful user interfaces for future digital environments.

Our study aims to fill the theoretical gaps in a robo-advisory context, which appears to be suited as it a) has proven its importance beyond hype and b) inherently contains both web personalization and website complexity. We thereby aim to improve the design of robo-advisors as users are currently still reluctant to invest through robo-advisors [17]. Having an optimized design is crucial not only for the robo-advisors aiming for increased investment intentions but also for users and society as a whole. Indeed, most users succumb to cognitive biases such as hyperbolic discounting, neglect to make savings, and risk making far-reaching sub-optimal financial decisions that negatively impact their financial security. In the future, this might even lead to negative outcomes also on a societal level-i.e., stressed pension schemes $[5,18]$. An enhanced understanding of the effects of website complexity and web personalization might help prevent this. Hence, we embark on this research guided by the research question: How do website complexity and web personalization affect users' intention to invest through robo-advisory?

To answer our research question, we draw on website complexity and web personalization literature and conduct an online experiment with 169 participants. Using a fictitious robo-advisor and re-building the first steps of a robo-advisory user journey, we analyze the main and interaction effects of website complexity and web personalization on users' investment intention. We contribute to IS research in two important ways.

First, our study sheds light on how personalization and complexity distinctly affect user behavior in digital environments and demonstrates the efficacy of combining both design elements. Although both personalization and complexity have been separately studied in previous IS research, little is known about how they operate together to improve users' behavior. Our findings support an interactive effect between these two design elements and highlight the importance of accounting for this interdependence when optimizing user interaction within digital environments. In this regard, we propose the combination of website complexity and web personalization as a novel design principle to overcome the potential negative effects of web personalization strategies.

Second, we contribute to the nascent research on user cognition in increasingly complex digital environments. Going beyond existing research focused on transactional purchase intention (e.g., in e-commerce), we demonstrate the impact of combining different interface design elements on user cognition in contexts with more far-reaching decisions such as robo-advisory. Turning to practice, we equip robo-advisors with recommendations on employing website complexity and web personalization simultaneously to increase users' investment intention.

\section{Theoretical Background}

\subsection{Robo-Advisory}

Often referred to as the "Fintech Revolution", the financial services sector has seen a growing number of innovations that radically change the way consumers approach and interact with financial services such as banking, investing, or insurance [19, 20, 21]. One particularly promising yet nascent technology is robo-advisory. Starting around 2008, robo-advisory has emerged as an opportunity for private investors who are comfortable using internet-based services yet want the reassurance of an investment advisor's guidance [22]. Robo-advisors provide automated financial advisory for a fraction of the costs of a real-life advisor [21]. Due to their high degree of automation, robo-advisors find themselves in a unique position that allows them to offer personalized portfolios to a broad audience, manage these portfolios, and provide dynamic investment recommendations that meet users' individual needs [5, 8]. Besides a significant level of personalization, complexity is an innate trait of robo-advisors due to their highly dynamic and sophisticated financial products. Thereby, robo-advisory marks an excellent context to study the combined effects of website complexity and web personalization. Robo-advisors' popularity is expected to rise on a steep curve, as their assets under management (AUM), one of the key metrics used to measure such business models, are expected to increase from $\$ 1$ trillion in 2020 [3] to $\$ 2.5$ trillion in 2024 [3]. Extant research on comparable advisory services (e.g., recommendation agents in e-commerce, decision support systems) has thus far identified numerous challenges for advisory providers such as lack of transparency, lack of trust, and information asymmetries [23, 24, 25]. However, adequate measures to tackle these challenges are yet to be found and validated. As robo-advisory is still 
in a phase of strong growth focused on acquiring new users, investment intention becomes an outcome that robo-advisors increasingly prioritize.

\subsection{Web Personalization}

User interfaces of IS are comprised of a mix of stimuli in the form of text, images, video, audio, and animations. These cues generate a cognitive reaction of the user based on their appearance and their content. Subsequently, users' behavior can be directed by the stimuli's design to achieve favorable outcomes. To maximize immediate and future business opportunities, providers of information systems often apply tactics like personalizing displayed content. In the context of websites, "[w]eb personalization generally refers to the process of adapting web content to meet the specific needs of users and to maximize business opportunities" [10, pp. 866-867]. One particularly prevalent approach to web personalization is user-driven web personalization. Within user-driven personalization, the user can explicitly specify their desired information requirements and presentation format through a website's features, tools, and options [9]. An example of this strategy is the music-streaming service Spotify, where a user can create playlists that match their taste in music. This paper will focus on the user-driven web personalization approach for two main reasons. First, due to the users' active involvement in a user-driven personalization process, their assessment of a website's value can be attributed more unambiguously to the displayed personalization cues [9]. Second, it is the most commonly applied tactic to adapt website content to users' preferences [26].

Prior research offers opposing views on the effectiveness of web personalization [10, 13]. Although much research has found evidence for positive outcomes of personalized service offers [27], these advantages come with preconditions and caveats that need to be addressed. One challenge that providers of IS are facing is the unresolved conflict between information privacy concerns and benefits derived from personalized service offers [28, 29, 13]. In contrast to most digital commerce contexts, robo-advisory represents a notably longer-term investment relationship. Thereby, it constitutes an especially important and under-researched context for web personalization.

\subsection{Website Complexity}

Besides personalization, complexity is an essential aspect of information systems. Drawing on Wood's [30] comprehensive framework of task complexity, Nadkarni and Gupta [14] propose the construct perceived website complexity as a measure of the complexity users experience when viewing a website. Their construct appears to be perfectly applicable for research on the design of information systems in general and robo-advisory in particular. Wood [30] defines perceived complexity as a linear combination of three dimensions that capture specific aspects: component, coordinative, and dynamic complexity. First, component complexity refers to dense and dissimilar information cues. On websites, density is represented by cues such as the length of text, the number of graphics, and the number of used colors. Dissimilarity is reflected by the usage of various formats such as texts, images, graphics, animations, and, more generally, by differing information items. Second, coordinative complexity is reflected in "a wide range of topics covered by the website, high number of webpages configuring a website, and many paths linking webpages" [14, p. 503]. Third, dynamic complexity is determined by the ambiguity and uncertainty of a website's content. Ambiguous content allows viewers to interpret the very same information in different ways, depending on personal background knowledge and usage context. In our study, website complexity refers to the sum of all three facets, as described by Nadkarni and Gupta [14].

Previous research in multiple domains has found that an adequate amount of complexity can improve desired outcomes. For instance, marketing researchers have found that a certain amount of complexity in visual figures within advertisements increases their overall effectiveness [31]. These findings entail that it is feasible to vary the complexity of an object to achieve a positive impact on user behavior, which highlights the need for further investigations of complexity as a critical attribute of information systems. Indeed, IS-related complexity research has mainly focused on immediate website-related outcomes such as satisfaction with the website $[14,32]$, perceived ease of navigation of the website [16], or avoidance towards the website [33]. In this paper, we examine the three mentioned facets of website complexity in the context of robo-advisory, as it offers a particular view on the effects of inherently complex information systems on user behavior.

\section{Research Model}

Our research model depicted in Figure 1 shows the main and direct effects of web personalization (H1) and website complexity (H2) on the users' investment intention. It also displays the interaction between website complexity and web personalization (H3). 


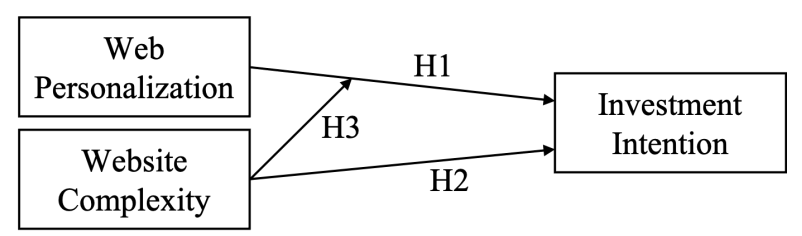

Figure 1. Research model.

\subsection{The Effect of Web Personalization on Investment Intention}

As introduced earlier, providers of IS can customize the content and appearance of their systems to influence their users' cognitive processes and improve desired business outcomes. Building on this basic principle, previous research has developed preference fit theory-an economic argument that a closer fit between consumers' preferences and product attributes entails increased benefits for consumers [34]. In this regard, perceived preference fit refers to "consumers' subjective evaluation of the extent to which a product's or service's features correspond to their preference system" [9, p. 231]. More specifically, preference fit improves when a consumer recognizes a substantial overlap between a products' advertised benefits and their own needs [35]. Web personalization tactics exploit this cognitive mechanism by adapting the displayed content to the user's preferences.

In recent years, the usage of such persuasion tactics has risen tremendously. An ever-growing number of online services is built around personalized content based on their users' behavioral data. Despite the benefits of personalization, providers of such services must ensure that their personalization strategy does not entail any undesired negative effects on users' behaviors. One particularly prominent example of these potential negative effects is described by the personalization privacy paradox $[11,12]$. Personalization is infeasible with requiring vast amounts of personal information and, thus, without a loss of privacy [12]. Kaniewska-Sejba and Pilarczyk [36] describe that participants respond to personalized marketing with a sense of violated privacy and display reluctance to share information, resulting in a negative perception of the service. However, this negative effect of website personalization is not consistently found in extant literature (e.g., [27]). For instance, Xu et al. [37] demonstrate that when the information disclosure is necessary for a personalized service and elicited in an overt and transparent way, it is less likely that privacy concerns are evoked.

Besides personalization, extant IS literature generally agrees that trust beliefs are a significant driver for desired user behavior (i.e., adoption decisions) - especially in the context of recommender agents [38, 39, 40]. Although prior research on this topic has found that perceived personalization can positively influence these trust beliefs (e.g., [27]), it remains unclear whether this holds true for contexts that exhibit a lower level of trust to begin with. While banks and governments are met with relatively high levels of trust, consumers tend to view internet companies as less trustworthy [41, 42]. In particular, upcoming online financial services (which typically do not possess the established reputation of reliability that banks enjoy) are met with lower levels of trust [43, 44]. Consequently, the influence of perceived personalization appears inconclusive and highly dependent on the context in which it is applied. Additionally, Wessel and Thies [45] report another negative effect: Personalization does not increase and may even decrease users' subsequent purchase intentions if users do not perceive that personalization as required to fulfill their needs. Hence, we argue that users' perception of web personalization during initial interaction with robo-advisors results in a negative impact on their investment decision.

H1: Users' intention to purchase an investment portfolio recommended by a robo-advisor will be higher after initially interacting with the robo-advisor during which web personalization is absent compared to an initial interaction during which it is present.

\subsection{The Effect of Website Complexity on Investment Intention}

We previously argued that an IS provider can positively influence a user's cognition by deliberately applying an adequate amount of website complexity in the system's appearance. Since the relevance of coordinative complexity is rather low in the context of robo-advisory, we focus on the remaining two facets, perceived component complexity and perceived dynamic complexity. In their current form, a robo-advisor's quality appears to be challenging to assess by current and potential future customers [46]. While evaluating personal investment strategies is arguably complicated in general, this is a particular challenge with robo-advisors for two reasons. First, during the initial interaction with an online service, the user has not yet had the opportunity to assess the eventual outcomes of the respective service offer. For instance, users who are initially interacting with a robo-advisor will be unable to assess the service's most important metric: future investment performance. This dilemma is further underlined by the long-term investment nature of a robo-advisor's recommended 
investment portfolio. Second, the actual investing procedure is entirely separate from the website that is presented to users. Consequently, the quality and complexity of the actual investment portfolio that robo-advisors offer are exceedingly complicated for their users to assess. Hence, whether a user intends to purchase such a portfolio falls into the domain of decision-making under uncertainty. According to Kahneman and Frederick [47], a person that is confronted with a highly complicated task often substitutes a part of the task to make it easier to complete. More precisely, they state that "judgment is mediated by a heuristic when an individual assesses a specified target attribute of a judgment object by substituting another property of that object - the heuristic attribute-which comes more readily to mind" [47, p. 4]. In our context, users substitute their assessment of the actual recommended investment portfolio with the assessment of the website they are viewing. As a result, manipulating the perceived website complexity of a robo-advisor's website allows influencing the perception of the advisor's total complexity. Extant literature on perceived complexity suggests that there exists a range of adequate complexity that positively influences desired outcomes. For example, when applied to website design, moderate complexity results in higher communication effectiveness in comparison to information cues with relatively low complexity [48]. In choice environments, an adequate amount of complexity (reflected in the number of alternatives the decision-maker can choose from) results in a high level of satisfaction for the decision-maker [15]. Furthermore, a comparable connection appears in the domain of human information processing, where a medium level of complexity maximizes task performance [49]. Against this backdrop of prior research, we argue that users who are exposed to website complexity in the context of robo-advisory are more likely to display a positive investment intention. Users perceive these complex cues as a substitute for the advisor's overall complexity.

H2: Users will be more likely to purchase a robo-advisor's recommended investment portfolio after initially interacting with the robo-advisor during which website complexity is present compared to an initial interaction during which it is absent.

\subsection{Interaction Effect of Website Complexity and Web Personalization}

In addition, we want to investigate the interaction effect of website complexity and web personalization on users' investment intentions. Previously, we explored the potentially negative effect that personalization has on investment decisions, possibly due to perceived privacy intrusion and diminished trust $[11,50]$. Consequently, trust-building strategies are a promising approach that IS providers can utilize to alleviate users' adverse reactions [29]. One promising trust-building strategy advisors can employ is to demonstrate how their data collection is justified for their sophisticated investment methods. Hence, by highlighting the complexity of its service, a robo-advisor can diminish the lack of transparency, increase levels of trust, and thus moderate the negative effect (i.e., loss of trust) of web personalization. Furthermore, more complex and sophisticated investment methods arguably present additional benefits and presenting them prominently during the initial user interaction will presumably lead to higher perceived benefits for the user. In turn, this perception of benefits will motivate users to disclose personal information despite existing (privacy) concerns. To summarize, we expect that complexity possesses the ability to moderate the negative impact of web personalization strategies.

H3: Website complexity will moderate the effect of web personalization such that it will attenuate or even cancel out the negative effect of web personalization on users' decision to purchase an investment portfolio recommended by a robo-advisor.

\section{Experiment}

\subsection{Treatment Design}

Extant literature on the design and implementation of experimental vignette methodology studies recommends using realistic treatments to ensure both internal and external validity [51]. We followed this by using a fictitious robo-advisor modeled upon existing robo-advisory websites. Our two independent variables, website complexity and web personalization, are already commonly used in practice by established advisory providers. For instance, bevestor, a German robo-advisor, allows their customers to personalize their portfolio by selecting "investment themes" [52]. Another European robo-advisor, Scalable Capital, uses highly complex information cues throughout their entire website [53]. Following their precedent, we designed the treatment for website complexity so that it resembles an informational graph on their website. As shown in Figure 2, the graph contained a complex-looking simulation of future portfolio developments and, thus, utilized the two facets of perceived website complexity we introduced previously: Perceived component complexity and perceived dynamic complexity. The 


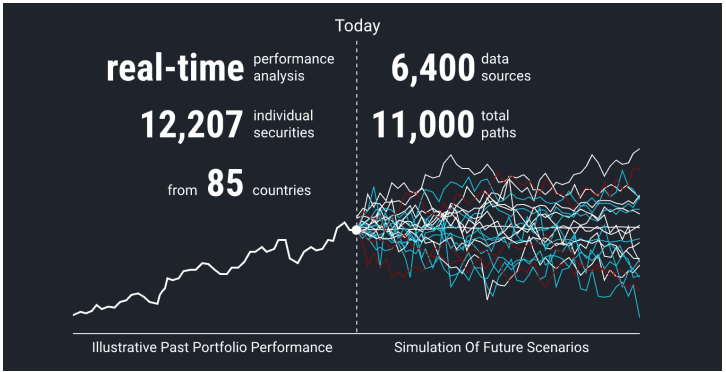

Figure 2. Treatment - website complexity present.

depiction of future scenarios in the graph implied uncertainty regarding the investment performance, and included claims such as "real-time performance analysis" provide a sense of ambiguity. Additionally, a high level of component complexity is reflected in the density and dissimilarity of the displayed information cues. The treatments for web personalization were designed following recommendations in prior literature on web personalization strategies $[9,54,55]$ and the design of bevestor's website [52]. Accordingly, we employed a user-driven website personalization approach and the personalization was entirely based on input given by the users. We presented each user with three mandatory questions about their investment preferences, along with a message stating that their responses will be used to create a personalized portfolio. In the last step, participants were presented with a list of funds that made up their fictitious investment portfolio. The selection of these funds was based on an authentic, real-world portfolio created by an investment expert to ensure that participants with previous experience in wealth management were not overly skeptical about the portfolio's validity. Above the funds, we displayed two buttons: "Buy Portfolio" and "Do Not Buy.", which were used to record our dichotomous dependent variable-investment intention.

\subsection{Experimental Design \& Procedure}

To answer our research question and test our hypotheses, we conducted a randomized online

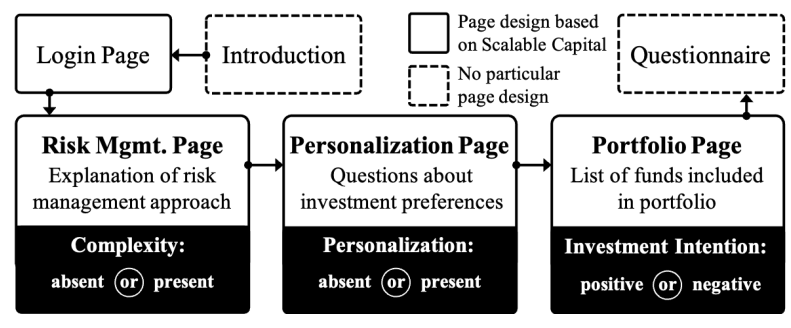

Figure 3. Experiment procedure. experiment in which we simulated the initial user interaction of a self-developed fictitious robo-advisor. We employed a 2 (website complexity: absent vs. present) $\times 2$ (web personalization: absent vs. present) full-factorial between-subjects design. In each treatment, the respective type of cues was either fully present or absent. The experiment procedure is illustrated in Figure 3. To control the subjects' personal experiences and avoid social desirability bias, we chose the experimental vignette methodology [51]. In line with existing research on vignette-based experiments and to prevent response biases, we asked the participants to put themselves in the shoes of a fictitious protagonist with the androgynous name Alex [56]. To evaluate the realism of our treatments, we successfully conducted a pretest with 17 participants.

\section{Results \& Analyses}

\subsection{Sample Description, Manipulation Checks \& Control Variables}

In line with previous research, we recruited 204 participants through the crowdsourcing platform Amazon Mechanical Turk [57]. In order to prevent any sampling biases, we did not preemptively restrict participation. To ensure a sufficient quality (and, therefore, a high validity) of our data, we filtered the submitted responses. In total, we employed four attention checks (e.g., we excluded respondents who completed the experiment within a significantly shorter than average amount of time). Our final data set consisted of 169 participants. The average age of our participants was 33 years, ranging from 22 to 70 years. Of the 169 participants, 37 (21.9\%) identified as female and $132(78.1 \%)$ as male. As control variables, we selected age, education, and privacy concerns. The items for privacy concerns were adapted from Chellappa and Sin [12]. Additionally, we conducted manipulation checks to ensure our treatments had the intended effects on the subject $[58,54]$. Our manipulation checks of web personalization confirmed that participants perceived the treatment with present cues as more personalized $(\mathrm{M}=4.89 ; \mathrm{SD}=1.38)$ than the treatment without them $(\mathrm{M}=5.58 ; \mathrm{SD}=0.97 ; \mathrm{F}=14.18 ; \mathrm{p}<0.001)$. Furthermore, our manipulation check for complexity indicated that the subjects perceived the robo-advisory process as complex when website complexity cues were present $(\mathrm{M}=4.58 ; \mathrm{SD}=1.80)$, while they did not perceive it as such without these cues $(\mathrm{M}=5.17$; $\mathrm{SD}$ $=1.15 ; \mathrm{F}=6.85 ; \mathrm{p}<0.05)$. The Cronbach's alpha for privacy concerns was 0.911 , which strongly suggests high construct reliability [59]. To address common method bias, we followed the recommendations of 
Podsakoff et al. [60]: First, we noted that participants should answer honestly and that there are no right and wrong answers. Second, we guaranteed anonymity for the evaluation. Third, we used different answer formats. We conducted a power analysis using $\mathrm{G}^{*}$ power 3.1 [61] with the following parameter specifications: four groups ( $2 \times 2$ full-factorial design), a moderate effect size, and a desired power level of .90 . The results indicated that a minimum sample size of 143 should be sufficiently powerful to detect significant effects [62, 63].

\subsection{Main Effect Analysis}

In line with extant IS research (e.g., [58, 57]), we conducted a three-stage hierarchical logistic regression on the dependent variable investment intention to test our hypotheses. As depicted in Table 1, in the first stage, we examined the effects of all control variables on the subjects' investment intention. Subsequently, we included both manipulations, personalization cues (PC) and complexity cues (CC), in stage 2 . In stage 3, we inserted the interaction term PC $\times \mathrm{CC}$. The results indicate significant effects of both manipulations.

Aside from our two manipulations, the level of education proves to have a significant influence. The higher a subject's level of education, the less likely they are to adopt our robo-advisor. This effect is statistically significant in all stages.

The results in stage 2 demonstrate two main effects on investment intention, supporting both $\mathrm{H} 1$ and $\mathrm{H} 2$. First, the presence of PC has a statistically significant negative effect on investment intention $(b=-1.296$; Wald statistic $(1)=4.086 ; \operatorname{Exp}(b)=0.274 ; p<0.05)$. In contrast, the presence of $\mathrm{CC}$ has a statistically significant positive effect on investment intention $(b=3.464$; Wald statistic $(1)=22.710 ; \operatorname{Exp}(b)=31.958 ; p<0.001)$. This indicates that users are almost 32 times more likely to display investment intention through our robo-advisor when they were presented with complexity cues as opposed to absent complexity cues.

\subsection{Interaction Effect Analysis}

Our third stage unveiled a significant two-way interaction of personalization and complexity $(\mathrm{b}=$ 3.636; Wald statistic $(1)=6.050 ; \operatorname{Exp}(b)=37.925$; $\mathrm{p}<0.05)$ on investment propensity, supporting our H3. The negative interaction terms suggest that the effect of personalization on the investment decision is attenuated when the user faced complexity cues. To further evaluate $\mathrm{H} 3$, we conducted a contrast analysis. The results depicted in Figure 4 highlight that when $\mathrm{CC}$ were absent, participants were less likely to invest when PC were present compared to when they were

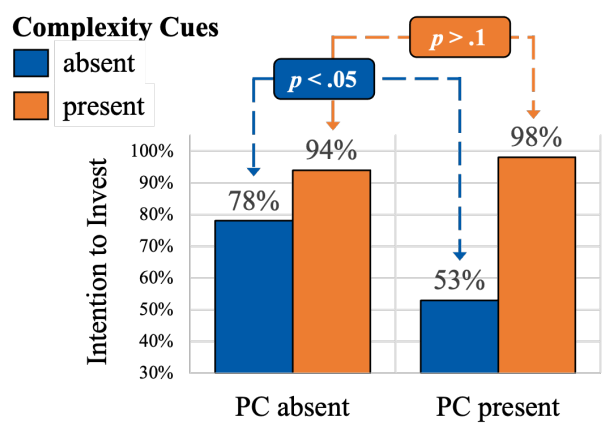

Figure 4. Investment decision when CC are absent vs. present.

absent $(53 \%$ vs. $78 \% ; \mathrm{F}=4.97 ; \mathrm{p}<.05)$. However, a significant difference in investment decision between the presence $(98 \%)$ and absence $(94 \% ; \mathrm{F}=1.25 ; \mathrm{p}>.1)$ of PC did not emerge when $\mathrm{CC}$ were present in support of $\mathrm{H} 3$.

\section{Discussion}

In light of the ongoing diffusion of digital technologies, providers of financial services face an ever-growing number of competitors while attempting to expand their reach into so far underrepresented customer segments. Combined with challenges posed by increasingly digitalized and automated services, providers are required to invest heavily in the optimization of their customer journey in order to convert mere visitors to valuable customers. The initial point of contact between provider and user presents a powerful opportunity to influence users' eventual investment decisions. By employing appropriate strategies and interface design elements, providers can lastingly shape the relationships between their users and their service offering. Our research explores the effects of a specific design strategy within the context of robo-advisory. We examine the impact of website complexity and web personalization on users' investment intentions within a robo-advisor. Our results show that website complexity can attenuate the negative effects of web personalization. While these negative effects are usually related to privacy concerns [11], we did not observe statistically significant differences in privacy concerns across our treatment groups. Thereby, other factors, for instance, investment-related factors like risk perception in our robo-advisory context, might be the reason for the negative impact of web personalization. Website complexity, as manipulated in this study, could further increase users' investment intention. These results suggest that our manipulation lies in the optimal range of complexity for the average 


\begin{tabular}{|c|c|c|c|c|c|c|}
\hline \multirow[b]{2}{*}{ Intercept } & \multicolumn{2}{|c|}{ Stage 1} & \multicolumn{2}{|c|}{ Stage 2} & \multicolumn{2}{|c|}{ Stage 3} \\
\hline & Coeff & SE & Coeff & SE & Coeff & SE \\
\hline Constant & 3.766 & 2.402 & 2.768 & 2.386 & 2.864 & 2.455 \\
\hline \multicolumn{7}{|l|}{ Manipulations } \\
\hline $\mathrm{PC}^{\mathrm{a}}$ & & & $-1.296^{*}$ & .641 & -2.325 & .793 \\
\hline $\mathrm{CC}^{\mathrm{a}}$ & & & $3.464 * * *$ & .727 & 1.631 & .890 \\
\hline $\mathrm{PC} \times \mathrm{CC}^{\mathrm{a}}$ & & & & & $3.636^{*}$ & 1.478 \\
\hline \multicolumn{7}{|l|}{ Control Variables } \\
\hline Privacy Concerns & -.669 & .348 & -.604 & .395 & -.596 & .415 \\
\hline Education & $-.714^{*}$ & .316 & $-.965 *$ & .391 & $-1.083^{*}$ & .445 \\
\hline Age & -.036 & .025 & -.047 & .032 & -.041 & .033 \\
\hline \multicolumn{7}{|l|}{ Model Fit } \\
\hline Nagelkerke's $R^{2}$ & & .272 & & .561 & & .607 \\
\hline -2 Log-Likelihood & & 22.063 & & 83.475 & & 76.401 \\
\hline Omnibus Test & & $689 * * *$ & & $3.277 * * *$ & & $.351 * * *$ \\
\hline
\end{tabular}

Table 1. Direct effect analysis - binary logistic regression analysis on investment intention.

participant, while a higher degree of website complexity might not necessarily further increase but instead decrease users' investment intention.

\subsection{Theoretical \& Practical Contributions}

With the presented study, we contribute to IS research and user interface research in digital environments in two important ways. First, our research illuminates how personalization and complexity not only distinctly affect user behavior but also how they interact. While both IS design elements have been widely researched in digital environments as individual drivers of e-commerce outcomes (e.g., [9, 16], researchers to date have neglected to study their interaction. We extend previous research by showing that personalization and complexity are interdependent, highlighting the importance of considering both in tandem when optimizing user interaction. More specifically, our results indicate that complexity attenuates and even compensates for the potential negative effect of personalization. We believe that is the case because complexity cues provide a justification why personalization and the connected personal information disclosure is necessary to increase the sophistication of robo-advisors' investment methods and thus how personalization benefits users. Second, we contribute to the emerging research on the impact of IS interface design on user cognition in complex digital environments. Our study shows the impact of interface design elements on user cognition and behavior in far-reaching decision environments such as robo-advisory (e.g., [5, 8]. From a practitioner's point of view, our study entails relevant implications for the design of robo-advisory. We show that the design needs to be carefully considered and demonstrate that personalization strategies in robo-advisory should be combined with website complexity during user's first interaction to increase long-term investment volumes.

\subsection{Limitations \& Future Research}

Despite the mentioned contributions, our study should be viewed as an initial foray into research on the perceived complexity of financial services. The presented experiment has a few noteworthy limitations that we want to address to acknowledge areas for possible improvements and hope to provide guidelines for future studies. First, the robo-advisor we used for our online survey was entirely fictional and, thus, our participants were not facing an actual investment decision with real-world financial consequences. It appears promising to increase external validity by repeating the experiment as a field study, including an existing robo-advisor and actual customers. Second, extant literature on the perception of complexity suggests that there exists a range in which the level of perceived complexity is optimal regarding desired outcomes. We explored this phenomenon with a linear perspective and concluded that too little complexity could be ineffective. In light of this relationship, it seems fruitful to determine the boundaries of the mentioned optimal complexity range. Furthermore, our results suggest that other factors, besides privacy concerns, lead to the negative impact of web personalization. Future research 
should study the effects of context-specific factors, like investment-related factors in our robo-advisory context, on web personalization. Hopefully, future studies will expand on our findings and solidify our collective understanding in the form of applicable design principles that guide practitioners towards a more user-oriented approach to increasingly complex products in digital financial services.

\section{References}

[1] R. Alt, "Evolution and perspectives of electronic markets," Electronic Markets, vol. 30, no. 1, pp. 1-13, 2020.

[2] A.T. Kearney, "Hype vs. reality: The coming waves of "robo" adoption," Report Insights from the A.T. Kearney 2015 Robo-Advisory Services Study, 2015. [Online]. Available: https://www.atkearney.com/documents/1019 2/7132014/Hype+vs.+Reality_The+Coming+Waves+of +Robo+Adoption.pdf

[3] Statista, "Robo-advisors," accessed 2020-08-18 [Online]. Available: https://www.statista.com/outlo ok/337/100/robo-advisors/worldwide

[4] P. Sironi, FinTech innovation: from robo-advisors to goal based investing and gamification. John Wiley \& Sons, 2016.

[5] M. Adam, J. Toutaoui, N. Pfeuffer, and O. Hinz, "Investment decisions with robo-advisors: the role of anthropomorphism and personalized anchors in recommendations," 2019.

[6] O. Entrop, M. McKenzie, M. Wilkens, and C. Winkler, "The performance of individual investors in structured financial products," Review of Quantitative Finance and Accounting, vol. 46, no. 3, pp. 569-604, 2016. [Online]. Available: https://doi.org/10.1007/s11156-014-0479-8

[7] N. Pfeuffer, M. Adam, J. Toutaoui, O. Hinz, and A. Benlian, "Mr. and mrs. conversational agent-gender stereotyping in judge-advisor systems and the role of egocentric bias," 2019.

[8] D. Jung, V. Dorner, F. Glaser, and S. Morana, "Robo-advisory," Business Information Systems Engineering, vol. 60, no. 1, pp. 81-86, 2018.

[9] A. Benlian, "Web personalization cues and their differential effects on user assessments of website value," Journal of Management Information Systems, vol. 32, no. 1, pp. 225-260, 2015.

[10] K. Y. Tam and S. Y. Ho, "Understanding the impact of web personalization on user information processing and decision outcomes," MIS Quarterly, pp. 865-890, 2006.

[11] N. F. Awad and M. S. Krishnan, "The personalization privacy paradox: an empirical evaluation of information transparency and the willingness to be profiled online for personalization,” MIS Quarterly, pp. 13-28, 2006.

[12] R. K. Chellappa and R. G. Sin, "Personalization versus privacy: An empirical examination of the online consumer's dilemma," Information Technology and Management, vol. 6, no. 2-3, pp. 181-202, 2005.

[13] T. B. White, D. L. Zahay, H. Thorbjørnsen, and S. Shavitt, "Getting too personal: Reactance to highly personalized email solicitations," Marketing Letters, vol. 19, no. 1, pp. 39-50, 2008.
[14] S. Nadkarni and R. Gupta, "A task-based model of perceived website complexity," MIS Quarterly, pp. 501-524, 2007.

[15] D. Te'eni, "Determinants and consequences of perceived complexity in human-computer interaction," Decision Sciences, vol. 20, no. 1, pp. 166-181, 1989.

[16] R. Mai, S. Hoffmann, U. Schwarz, T. Niemand, and J. Seidel, "The shifting range of optimal web site complexity," Journal of Interactive Marketing, vol. 28, no. 2, pp. 101-116, 2014.

[17] D. Jung, V. Dorner, C. Weinhardt, and H. Pusmaz, "Designing a robo-advisor for risk-averse, low-budget consumers," Electronic Markets, vol. 28, no. 3, pp. 367-380, 2018.

[18] J. Skinner, "Are you sure you're saving enough for retirement?" The Journal of Economic Perspectives, vol. 21, no. 3, pp. 59-80, 2007. [Online]. Available: www.jstor.org/stable/30033735

[19] P. Gomber, R. J. Kauffman, C. Parker, and B. W. Weber, "On the fintech revolution: Interpreting the forces of innovation, disruption and transformation in )nancial services," Journal of Management Information Systems, vol. 35 , no. 1 , pp. 220-265, 2018 .

[20] C. Haddad and L. Hornuf, "The emergence of the global fintech market: Economic and technological determinants," Small Business Economics, vol. 53, no. 1, pp. 81-105, 2019.

[21] I. Lee and Y. J. Shin, "Fintech: Ecosystem, business models, investment decisions, and challenges," Business Horizons, vol. 61, no. 1, pp. 35-46, 2018.

[22] M. L. Fein, "Robo-advisors: A closer look," Available at SSRN 2658701, 2015.

[23] P. Nussbaumer, I. Matter, G. R. à Porta, and G. Schwabe, "Designing for cost transparency in investment advisory service encounters," Business Information Systems Engineering, vol. 4, no. 6, pp. 347-361, 2012.

[24] P. Nussbaumer, I. Matter, and G. Schwabe, "“enforced" vs."casual" transparency-findings from it-supported financial advisory encounters," ACM Transactions on Management Information Systems (TMIS), vol. 3, no. 2, pp. 1-19, 2012.

[25] C. Ruf, A. Back, and M. Burkhardt, "Mobile first auch in beratungsprozessen des private banking? entwicklung und validierung einer ipad-applikation,” 2016.

[26] Fast Company, "Robo-advisor betterment is on a personalization push as it surpasses $\$ 10$ billion in aum," accessed 2020-08-18. [Online]. Available: https: //www.fastcompany.com/40442080/robo-advisor-better ment-is-on-a-personalization-push-as-it-surpasses- 10 -billion-in-aum

[27] S. Y. Komiak and I. Benbasat, "The effects of personalization and familiarity on trust and adoption of recommendation agents," MIS Quarterly, pp. 941-960, 2006.

[28] M. Adam and J. Klumpe, "Onboarding with a chat-the effects of message interactivity and platform self-disclosure on user disclosure propensity," 2019.

[29] E. Aguirre, D. Mahr, D. Grewal, K. de Ruyter, and M. Wetzels, "Unraveling the personalization paradox: The effect of information collection and trust-building strategies on online advertisement effectiveness," Journal of Retailing, vol. 91, no. 1, pp. 34-49, 2015. 
[30] R. E. Wood, "Task complexity: Definition of the construct," Organizational Behavior and Human Decision Processes, vol. 37, no. 1, pp. 60-82, 1986.

[31] B. J. Phillips and E. F. McQuarrie, "Beyond visual metaphor: A new typology of visual rhetoric in advertising," Marketing theory, vol. 4, no. 1-2, pp. 113-136, 2004.

[32] S. Sohn, B. Seegebarth, and M. Moritz, "The impact of perceived visual complexity of mobile online shops on user's satisfaction," Psychology \& Marketing, vol. 34 no. 2, pp. 195-214, 2017.

[33] L. Deng and M. S. Poole, "Affect in web interfaces: A study of the impacts of web page visual complexity and order," Mis Quarterly, pp. 711-730, 2010.

[34] I. Simonson, "Determinants of customers' responses to customized offers: Conceptual framework and research propositions," Journal of Marketing, vol. 69, no. 1, pp. $32-45,2005$.

[35] M. Schreier, "The value increment of mass-customized products: an empirical assessment," Journal of Consumer Behaviour, vol. 5, no. 4, pp. 317-327, 2006.

[36] A. Kaniewska-Sejba and B. Pilarczyk, "Negative effects of personalization in direct marketing," International Journal of Arts Sciences, vol. 7, no. 2, p. 89, 2014.

[37] H. Xu, X. R. Luo, J. M. Carroll, and M. B. Rosson, "The personalization privacy paradox: An exploratory study of decision making process for location-aware marketing," Decision Support Systems, vol. 51, no. 1, pp. 42-52, 2011.

[38] I. Benbasat and W. Wang, "Trust in and adoption of online recommendation agents," Journal of the Association for Information Systems, vol. 6, no. 3, p. 4, 2005.

[39] D. Gefen, E. Karahanna, and D. W. Straub, "Trust and tam in online shopping: An integrated model," MIS Quarterly, vol. 27, no. 1, pp. 51-90, 2003.

[40] D. H. McKnight, V. Choudhury, and C. Kacmar, "Developing and validating trust measures for e-commerce: An integrative typology," Information Systems Research, vol. 13, no. 3, pp. 334-359, 2002.

[41] T. Dinev and P. Hart, "Privacy concerns and levels of information exchange: An empirical investigation of intended e-services use," e-Service Journal, vol. 4, no. 3, pp. 25-60, 2006.

[42] C. Lutz and P. Strathoff, "Privacy concerns and online behavior-not so paradoxical after all? viewing the privacy paradox through different theoretical lenses," Viewing the Privacy Paradox Through Different Theoretical Lenses (April 15, 2014), 2014.

[43] Y. Wang, Y. Wang, H. Lin, and T. Tang, "Determinants of user acceptance of internet banking: an empirical study," International Journal of Service Industry Management, 2003.

[44] S. Yousafzai, J. Pallister, and G. Foxall, "Multi-dimensional role of trust in internet banking adoption," The Service Industries Journal, vol. 29, no. 5, pp. 591-605, 2009.

[45] M. Wessel and F. Thies, "The effects of personalization on purchase intentions for online news: An experimental study of different personalization increments," 2015.

[46] M. Faloon and B. Scherer, "Individualization of robo-advice," The Journal of Wealth Management, vol. 20, no. 1, pp. 30-36, 2017.
[47] D. Kahneman and S. Frederick, "Representativeness revisited: Attribute substitution in intuitive judgment," Heuristics and biases: The psychology of intuitive judgment, vol. 49, p. 81, 2002.

[48] G. Geissler, G. Zinkhan, and R. T. Watson, "Web home page complexity and communication effectiveness," Journal of the Association for Information Systems, vol. 2, no. 1, p. 2, 2001.

[49] H. M. Schroder, M. J. Driver, and S. Streufert, Human information processing: Individuals and groups functioning in complex social situations. Holt, Rinehart and Winston, 1967.

[50] F. Bélanger, J. S. Hiller, and W. J. Smith, "Trustworthiness in electronic commerce: the role of privacy, security, and site attributes," The Journal of Strategic Information Systems, vol. 11, no. 3-4, pp. 245-270, 2002.

[51] H. Aguinis and K. J. Bradley, "Best practice recommendations for designing and implementing experimental vignette methodology studies," Organizational Research Methods, vol. 17, no. 4, pp. 351-371, 2014.

[52] bevestor, "Investment themen," accessed 2020-08-18 [Online]. Available: https://www.bevestor.de/investment -themen/

[53] Scalable Capital, "Better risk management," accessed 2020-08-18. [Online]. Available: https://uk.scalable.capi tal/better-risk-management

[54] O. F. Koch and A. Benlian, "Promotional tactics for online viral marketing campaigns: How scarcity and personalization affect seed stage referrals," Journal of Interactive Marketing, vol. 32, pp. 37-52, 2015.

[55] P. Terres, J. Klumpe, D. Jung, and O. Koch, "Digital nudges for user onboarding: Turning visitors into users," 2019.

[56] A. J. Nederhof, "Methods of coping with social desirability bias: A review," European Journal of Social Psychology, vol. 15, no. 3, pp. 263-280, 1985.

[57] K. Roethke, J. Klumpe, M. Adam, and A. Benlian, "Social influence tactics in e-commerce onboarding: The role of social proof and reciprocity in affecting user registrations," Decision Support Systems, 2020.

[58] J. Klumpe, O. F. Koch, and A. Benlian, "How pull vs. push information delivery and social proof affect information disclosure in location based services," Electronic Markets, pp. 1-18, 2019.

[59] C. Fornell and D. F. Larcker, "Evaluating structural equation models with unobservable variables and measurement error," Journal of Marketing Research, vol. 18, no. 1, pp. 39-50, 1981

[60] P. M. Podsakoff, S. B. MacKenzie, J.-Y. Lee, and N. P. Podsakoff, "Common method biases in behavioral research: A critical review of the literature and recommended remedies," Journal of Applied Psychology, vol. 88, no. 5, p. 879, 2003.

[61] F. Faul, E. Erdfelder, A. Buchner, and A.-G. Lang, "Statistical power analyses using $\mathrm{g}$ * power 3.1: Tests for correlation and regression analyses," Behavior research methods, vol. 41, no. 4, pp. 1149-1160, 2009.

[62] J. J. Baroudi and W. J. Orlikowski, "The problem of statistical power in mis research," MIS Quarterly, pp. 87-106, 1989 .

[63] J. Cohen, "A power primer," Psychological Bulletin, vol. 112 , no. 1, p. $155,1992$. 